\title{
ON THE COEFFICIENTS OF ABSORPTION OF THE ATMOSPHERIC GASES IN DISTILLED WATER AND SEA WATER \\ BY
}

\author{
CHAS. J. J. FOX
}

\section{PART I: Nitrogen and Oxygen}

The present publication contains an account of the first part of an investigation into the solubility of Nitrogen and Argon, Oxygen and Carbonic Acid in sea-water; namely the absorption coefficients of Nitrogen and Argon and of Oxygen. It is known that these gases have the same molecular weight dissolved as in the Gaseous state and are dissolved without chemical reaction; for these reasons Henry's Law holds and indeed between wide limits ${ }^{1}$ ). In the case of the Carbonic Acid, conditions are different. In the first place the partial pressure of the Carbonic Acid in the atmosphere is much smaller, in fact only $1 / 2600$ that of the Nitrogen and $1 / 700$ that of the Oxygen; and sea-water is alkaline as is well known, and therefore reacts with the Carbonic Acid. The consequence is that Henry's Law cannot hold; except perhaps over narrow limits. It is therefore clear that the nature of the problem is quite different in the case of the Carbonic Acid and must be investigated by different methods; and it is convenient to include in the present communication the determinations of Nitrogen and Oxygen and to reserve Carbonic Acid for separate publication.

The method employed for Nitrogen and Oxygen is a modified form of Estreicher's ${ }^{2}$ ) adaptation of OsTwald's ${ }^{3}$ ) method. The burette $A$ at its upper end bears a two-way tap $a$, on the one hand connecting it to the tube $D$ through which the gas for investigation is to be admitted to the burette; on the other hand the tap a connects the burette by means of the spiral $C$ to the bulb $B$ which contains the known quantity of water, of which the solubility coefficients for the gas, are to be determined. The spiral is of very thin glass and therefore very elastic; it allows the bulb to be agitated violently without risk of breakage.

1) See VAx'T HoFf, Vorlesungen über theoretische und physikalische Chemie Braunschweig 1898. Zweites Heft p. $20 \mathrm{ff}$.

2) Estreicher Zeitschrift für physikalische Chemie 31 p.176.

$\left.{ }^{3}\right)$ Ostwald-Luther, Physiko-chemische Messungen p. 274. 
By means of the tap $c$, the spiral and the burette can be exhausted, by connecting the tube $E$ with a Toplen's mercury-pump. Evacuation having been accomplished in this way, the tap $c$ is closed and the gas to be investigated is allowed to come into the Burette through the tube $D$, by way of the taps $d$ and $a$. The tube $D$ is capillary $(1 \mathrm{~mm}$. dm.); its volume between the two taps $a$ and $d$ is very small and found easily and accurately, merely by calculation from its length and diameter. Before $E$ is connected to the mercury-pump this capillary is filled with water between $a$ and $d$, which are then closed; this water is carried subsequently into the burette when the gas to be investigated is admitted. The object of this water is to keep the gas in the burette at all times saturated with water vapour. The manipulation of the mercury and the measurement of the pressure are provided for by means of a mercury reservoir and pressure tubing, connected to the burette by means of a glass tube $F$ melted in at the bottom and another tube $G$ identical with $A$, divided into linear millimeters and provided with an ordinary glass tap $g$, at the top, which opens directly to the Atmosphere.

All connections referred to in the present work were made by sealing the glass tubes together with the blowpipe; and this is always to be understood unless otherwise explicitly stated.

It is quite clear that the perfection with which the final traces of air are removed from the burette, spiral and bulb is of paramount importance in the attainment of high accuracy. In the case of the burette and spiral, evacuation is of course accomplished satisfactorily beyond question by means of the mercury-pump. But the simple method which Estreicher employed for freeing the bulb and water from air was found upon examination to be unreliable. Before filling the bulb with water for the investigation, Estreicher put in a few cc. of mercury with the object of improving the mixing, on agitation, and of so increasing the rate of absorption. The present writer found this to be unnecessary; in practice it was found that 5-10 minutes continual agitation was sufficient always to ensure equilibrium between gas and water. As a rule the bulb was shaken for 5 minutes and a reading taken, then shaken again and another reading taken; it was only very seldom that these two readings differed. If such were the case however, the shaking was continued for another 5 minutes and another reading taken.

Estreicher filled the bulb, the volume and weight of which were determined beforehand, with water (and the few cc. of mercury), connected it directly by means of india-rubber pressure tubing to an ordinary water-pump and boiled until about a quarter of the water had evaporated away; the tap was at this point closed and the bulb weighed again. On shaking the bulb now, the water hits the glass, in the vacuum, with the characteristic crackle. As a matter of fact 
however, this simple method of Estreicher's does not give a perfect vacuum and a bubble of air 3-6 millimeters in diameter is left behind invariably; the crackling sound adopted by Estreicher in his method as the criterion of complete evacuation, is in fact, misleading. If the bulb so evacuated be opened under a mercury surface with all suitable precautions, mercury should enter the bulb and fill it; but a small residual bulb of air is always left. It is of course a well-known fact that it is not easy to obtain perfectly air-free water or in fact an air free space of ary kind; it might be expected, however, that boiling and evacuating employed together, in this way, should be successful if only carried out properly and continued long enough. But an exhaustive and critical examination showed that this method always leaves a residual air-bubble of about $0.01-0.1 \mathrm{cc}$. It was noticed that under these circumstances it is very difficult to get the water to boil away tranquilly and evenly; it bumps badly even when warmed gently in a luke warm water-bath. In addition, it is very difficult to get a water pump to work quite evenly, owing to the inconstancy of the water supply; and the result is that a quantity of water always collects in the rubber tubing, where it works up and down, in effect like a sort of piston, which makes it difficult for the final traces of air to make their way out. It is suggested that Estreicher's values for Argon and especially Helium, may be subject to a small error due to this fact. If so it might be possible that his values for Argon are too small by something between about $0.2-5 \%$, for Helium by about $0.5-10 \%$.

WINKLER $^{1}$ ) as a result of some theoretical considerations which are however, admittedly not quite conclusive, has also suspected that ESTREICHER's Helium values are possibly not quite so reliable as are those accepted for some other gases. It is therefore to be hoped that these determination will be repeated.

The two weighings, before and after filling, and the known volume of the bulb give the data for calculating the volume of water taken and the free-space above the water. This latter free-space filled with water vapour, varies with the temperature owing to the different rates of expansion of water and glass; and its volume is calculated easily for any temperature when these two temperature coefficients are known. The cubic temperature coefficient of the glass bulbs employed was actually determined by experiment to be 0.0000239 between $0^{\circ}$ and $50^{\circ}$. The specific volumes of the destilled water at the different temperatures employed, were taken from Landolt and Börnsteis's Tables (3. Aufgabe 1905); in the case of sea-water the values were taken from Knudsen's Hydrographic Tables, Kopenhagen 1901 p. 39-46.

1) L. W. WinkLeR Zeitschrift für physikalische Chemie 55 p. 344. 
In the present experiments the bulb was evacuated as follows. By means of a piece of thick pressure tubing, the bulb $A$ (Fig. 2) was connected to the tube $B$, and the bulb and about $1 / 3$ of the tube then filled with the water to be investigated. The water-pump was applied to the upper end of the tube $B$. The water in both $A$ and $B$ were kept boiling in the vacuum say for 10-15 minutes; $A$ was then of course quite full of air-free water. But it is desirable that it should be not too full; otherwise the area of water-surface to be exposed to the gas in the actual experiment, will be so small that mixing will be difficult and the rate of solution slow. In practice about $10 \mathrm{cc}$. of free-space is convenient, and in the method here described it may be adjusted at that or any other value as desired, by deflecting and partially inverting the bulb while still connected by the tubing to the tube $B$, so that a bubble of steam instead of rising to the water-surface in $B$ may collect inside the bulb. When this steam-bubble of the size desired has collected, the tap is closed and the bulb disconnected from the tubing. On now opening under a mercury surface, the bulb will fill completely and not the faintest trace of air will be observable. It will also be noticed that the water hits the glass on shaking, with a report somewhat alarming in its intensity; much harder in fact than is the case when the evacuation is carried out in the simple method described by Estreicher. There is only one difficulty in the carrying out of the method, and that is that the boiling is rather hard on the grease used for lubricating the $\operatorname{tap}^{1}$ ). The tap must be very evenly and not too freely greased; most of it will in the process of boiling be carried up by the rising water to the surface, but enough will remain to hold the tap closed tightly, at all events if the tap be well selected.

It is necessary to make the sea-water quite neutral before introduction into the bulb otherwise the Carbonic Acid will, continue to be evolved the whole time, and it will be impossible to evacuate; insoluble carbonates too, would be precipitated. To accomplish this, the alkalinity of the sea-water was determined accurately by boiling $1 / 2$ litre with a known quantity of acid in excess, and then titrating backwards (using standard alkali solution with Phenolphthalein as indicator). The exact necessary quantity of acid - a mixture of Hydrochloric and Sulphuric Acid in the proportion of $\mathrm{Cl}$ to $\mathrm{SO}_{4}$ in sea-water - was then calculated and added to the original sample of sea-water, so as to make it just neutral. The amount required, is always so small that it is without effect upon the ratio of chlorine to specific gravity.

The bulb having been filled satisfactorily with the water to be investigated, it is sealed on to the spiral; $A$ and $G$ having been filled

1) The grease employed was the now well known rubber grease (OstwaldLuther, Physiko-chemische Messungen p. 154 and Traver's Experimentelle Untersuchungen von Gasen. Braunschweig, 1905 p. 24). 
with mercury up to the taps, and the capillary $D$ with water between the taps $a$ and $d$ which are then closed, the tube $E$ is sealed on to another tube leading to the Töpler pump as well as to the gas-holder ( $K$ Figs. 3 and 4 ), containing the gas for the measurements. The spiral and adjoining tubes are exhausted thoroughly; the tap $c$ is then closed and the tap belonging to the pump also. This done, the tap $k$ of the gas-holder is opened so that gas passes from the gas-holder up as far as the taps $d$ and $c$ and then afterwards by opening $d$ and $a$ into the burette $A$; the water contained in the capillary between the taps $d$ and $a$ is of course swept in with it. All this gas is then removed again by the pump with the object of washing out any traces of foreign gases (air e.g.) which may happen to have been occluded on the glass. Before doing this the small quantity of water is always brought back to the tap $d$ and the latter closed, before putting into communication with the pump. Finally the burette is filled with the gas, the tap $a$ closed and the tube $E$ then cut with the glass knife. The apparatus which, by means of attachments to the lid, was suspended in the air during these operations (balanced by a chain running to a counterpoise, over pulleys hanging from the ceiling) is at this stage lowered into the big beaker $M$ which serves as a waterbath. It is fitted with an Ostwald Toluol thermo-regulator and an air-blast for blowing a stream of bubbles through, to ensure good circulation (not shown in Figure). A thermometer graduated in tenths of a degree, with corrections from the Physikalische Reichsanstalt, allowed the temperature of the bath to be read off, correct to one or two hundredths, with the same telescope as was used for reading off the gas in the burette ${ }^{1}$ ):

During the measurements, the tap $g$ must be kept open the whole time to the Atmosphere. The pressure under which the gas in the burette is measured, is of course known from the difference of level of the two mercury menisci in $G$ and $A$. The two scales - in linear millimeters - must be compared with one another; simply by opening both $A$ and $G$ to the Atmosphere and by reading off the mercury levels in each of the tubes, with the mercury adjusted by means of the Reservoir, successively at several different points on the scale.

The burette $A$ was calibrated beforehand, so that its volume up to any point of its linear millimeter scale could be read off from a table. For this calibration, $A$ was cut off with the glass knife, from the rest of the instrument, a glass tap was melted on at the bottom and the whole burette filled with mercury. By now running out successive small portions of mercury and weighing each time, by reading off the gra-

1) The 300 millimetre scales on these tubes were very exactly and finely made by Gustav Mưller, Ilmenau. Then had a volume each of about 21 cc. 
duation at which the mercury niveau rests at each weighing, the necessary data for finding the volume up to any graduation were obtained and then tabulated.

The gases for the determination, Atmospheric-Nitrogen (i. e. Nitrogen containing Argon) and Oxygen, were stored up in the gasholder $K$ (Figs. 3 and 4 ) from whence they could be admitted to the burette $A$, as desired, through the tap $k$ and the tube $E$. The Nitrogen was prepared in some experiments by passing air over red-hot copper gauze, and then over soda lime and phosphoric pentoxide as illustrated (Fig. 3). Air was drawn into $L$ from the open atmosphere by means of the $\operatorname{tap} l$, which was then turned the other way so that the air collected was put into contact with hot copper contained in the tube $p$; it was thence passed on through $q$ containing soda-lime and $r$ containing pure phosphoric oxide, to the gas-holder $K$ quite similar to $L$. From $K$ it was passed back again the same way to $L$, and the operation repeated over again several times. In other experiments the copper gauze was replaced by white phosphorus contained in a tube of the same shape as $p$ which was however in this case made of Jena Geräte Glas and joined to $L$ and $q$ by thick india rubber pressure tubing instead of being melted on with the blowpipe. The phosphorus was warmed beforehand with a lighted match and, the reaction itself then provided sufficient heat to keep it going. This was found more convenient on the whole, than the copper gauze, which when ordinary glass tubing is used, requires rather a nice adjustment of the pressure to prevent the glass either from being blown out or in when hot. The copper gauze too, must be reduced each time or else it does not work so well. Both methods gave quite the same results for the case of distilled water and subsequently the phosphorus only was employed, as being the more convenient.

According to Travers ${ }^{1}$ ) the most frequently met impurity of chemically prepared Nitrogen is a trace of Nitric Oxide; which however, is decomposed at high temperatures in contact with copper, phosphorus etc. and would therefore not be formed in the present instance.

For the preparation of the Oxygen, pure potassium permanganate was used (Travers loc. cit. p. 43). It was contained in a soda-glass tube $s$ melted on to $q$, in the place of the gas-holder $L$ and the tube $p$, used for the Nitrogen. It was also provided with a Mercury Manometer and melted on to the TöPLER's mercury-pump. 'To collect pure Oxygen for use in the experiments, the gas-holder $K$ is first filled up to the $\operatorname{tap} k$ with mercury and $S, q, r$, then evacuated by the pump. On now warming the permanganate in $S$, Oxygen is gene-

1) M. W. Travers, Experimentelle Untersuchung von Gasen, deutsch von Estreicher. Braunschweig 1905 p. 47. 
rated, collected in $K$ and allowed to stand for a time, so that gas occluded on the glass walls may be replaced by Oxygen. The Oxygen is then pumped out again and a fresh quantity generated; it is repeated several times, to make sure that there is only pure Oxygen present and the quantity for experiment is then collected in $K$ for use.

The bulb having been filled with the water for the experiment (Distilled water or Sea-Water) highly evacuated, melted on to the spiral and bound firmly by copper wire, in place, on the brass rod by which it is to be agitated when in the water bath; the spiral and adjoining tubes having been evacuated by the pump, the gas is admitted to the burette together with the small quantity of water in the capillary tube $D$ (the burette rinsed out once or twice with the gas, as described above). The taps $a$ and $d$ having been closed and $g$ opened, $E$ is cut with the glass knife and the apparatus then lowered into the water-bath in the way described above. The beaker rests on a -tripod which stands on a board bearing levelling screws, so that the two graduated tubes which are very near to one another and parallel, may also always be placed in the same vertical position. This is assured easily enough by means of a series of marks, plumb line, spirit level etc. suitably arranged.

By means of a telescope in front and a light placed behind the beaker, the temperature indicated by the thermometer is read off, then the mercury levels in the two tubes and finally the temperature again. This series of readings is then repeated two or three times at intervals of a few minutes. This having been done the tap $a$ is then turned so that the gas flows into the spiral $c$ up as far as the tap $b$.

The Volume of the spiral is given by the expression

$$
\text { Vol. of spiral at } t_{2}^{0}=\frac{p_{1}}{p_{2}} \cdot \frac{273+t_{2}}{273+t_{1}} \cdot V_{1}-V_{2}
$$

Where $P_{1} V_{2}$ are the volumes indicated by the burette readings before and after opening the tap $a, p_{1} p_{2} t_{1} t_{2}$ the corresponding corrected pressures and temperatures.

A new series of readings is then taken in the same way as before and finally the tap $b$ of the bulb opened to the gas. The bulb is agitated vigorously with the hand by means of the lever $t$ for 5 minutes, and a reading then taken; it is then shaken again for $\tilde{\jmath}$ minutes and another reading taken, which as a rule did not differ from the first reading. If it did however, shaking for another 5 minutes always gave the same reading as the second. Then the temperature of the bath was altered by about 5 degrees (the thermoregulator adjusted suitably) and the readings continued in the same way. In some experiments the order of taking the temperatures was air temperature $\left(14^{\circ}-25^{\circ}\right.$ about) $25^{\circ}, 35^{\circ}, 45^{\circ}, 50^{\circ}, 40^{\circ}, 30^{\circ}, 20^{\circ}, 10^{\circ}$, 
$5^{\circ}, 0^{\circ}$. The idea of this was that if phenomena connected with overor under-saturation were of any importance, it would be discovered at once by a resulting regular uneveness of the solubility curves. No such effect was ever noticeable and when this fact had been ascertained the temperature order was altered so that the low temperatures were all taken before the high ones; and because it was noticed that the grease of the taps softened considerably at higher temperatures, so that there appeared a slight risk of losing a series of determinations from that cause. This never happened fortunately. The barometer was read about every hour as a rule; more frequently if necessary. After the series of observations had been taken, the bulb was cut off from the apparatus and in the case of sea-water samples, the Chlorine of the water determined by titration (MoHR's method and KNudsEn's tables with Normal-Water).

The apparatus has slight advantages over that employed by ESTREICHER. It is with the present apparatus not necessary always to read off the gas volume at atmospheric pressure, as Estreicher had to do. In practice it is very difficult to get water and gas just in equilibrium just at atmospheric pressure. By having the two graduated tubes as used here, it is possible to take any pressure and to vary it as desired (within a range of 300 millimeters). It is then, possible to set the mercury levels just about where they are desired, then to agitate the bulb until equilibrium is reached and to read off at whatever final position the mercury has taken up. This is much easier in practice and must be more accurate. It is especially of importance in the case of Oxygen which, as is well known, it is peculiarly difficult to measure with high precision in contact with a mercury surface. The reasons for this, which are somewhat obscure, are no doubt connected with Oxygen's remarkable activity chemically. In the present case it is possible by having two graduated tubes, to make sure that such possible errors are excluded, merely by making each determination at two or three different pressures. In the present case too, the quantity of water taken is greater than in the case of Estreicher's Experiments $(130 \mathrm{cc}$. instead of about $80 \mathrm{cc}$.). To keep the gas in the burette always saturated with water vapour, Estreicher by suitable manipulation got a few drops over from the bulb through the spiral. In the apparatus here employed a known quantity was added beforehand by filling the tube $D$. This was found much more convenient in practice.

Finally, it should be stated that the apparatus was used and tested for several weeks and many series of determinations taken and rejected, before it was considered that everything was in perfect order and satisfactory. Then the actual determinations, particulars of which it is the purpose of the present paper to describe, were made. 
The measurements of Nitrogen and Oxygen in distilled water are given in detail to illustrate the method.

Only the final results of the determinations in sea-water are given and at the same time the values as found from the formula calculated from the observations. Tables 1 and 2 contain the determinations for Nitrogen and distilled water, Table 3 for Nitrogen and seawater of Chlorine concentration 7.25, 15.32, $23.41 \%$. Tables 4 and 5 contain the determinations of Oxygen in distilled water and Table 6 of Oxygen in sea-water of Chlorine concentration 7.68, 14.27, 20.31\%. In calculating these values from the observations the average composition of Air, freed from water vapour and carbonic acid, was assumed to be $79.10 \%$ Nitrogen and $20.90 \%$ Oxygen, by Volume.

The interpolation formulae calculated from these observations between $0^{\circ}$ and $30^{\circ}$ are for Nitrogen

$$
\begin{array}{r}
\mathrm{N}_{2}=18.561-0.4280 t+0.0074527 t^{2}-0.00005494 t^{3} \\
-\operatorname{Cl}\left(0.2149-0.007117 t+0.0000952 t^{2}\right)
\end{array}
$$

for Oxygen

$$
\begin{array}{r}
\mathrm{O}_{2}=10.291-0.2809 t+0.006009 t^{2}-0.0000632 t^{2} \\
-\mathrm{Cl}\left(0.1161-0.003922 t+0.000063 t^{3}\right) .
\end{array}
$$

Table 1

A tmospheric Nitrogen in distilled water

Volume of bulb empty at $0^{\circ}=138.686=v_{0}$.

Volume of water taken at $0^{\circ}=123.498=w_{0}$.

Volume of gas taken, $N_{\mathbf{z}}$ (corrected) $=17.630 \mathrm{cc}$. at $9^{\circ} .80$ and $857.95 \mathrm{~mm}$.

$$
=19.2124 \text { at } 0^{\circ} .760 \text {. }
$$

\begin{tabular}{|c|c|c|c|c|c|c|c|c|c|c|c|}
\hline$t$ & $w_{t}$ & $v_{t}$ & 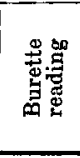 & 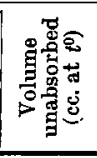 & 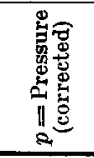 & 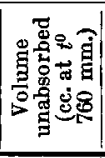 & 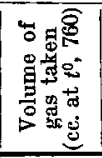 & 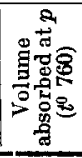 & 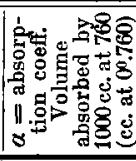 & 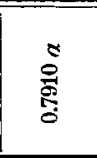 & 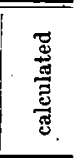 \\
\hline 0.53 & 123.510 & 138.689 & 2.410 & 21.832 & 59.220 & 17.012 & 19,250 & 2.238 & 23.21 & 18.36 & 18.34 \\
\hline 6.00 & 123.502 & 138.705 & 2.788 & 22.235 & 60.100 & 17.583 & 19.635 & 2.052 & 2056 & 16.26 & 16.25 \\
\hline 10.00 & 123.531 & 138.719 & 3.330 & 22.762 & 60.107 & 18.002 & 19.916 & 1.914 & 18.90 & 14.94 & 14.97 \\
\hline 15.72 & 1.23 .619 & 138.739 & 3.454 & 22.818 & 61.550 & 18.480 & 20.319 & 1.839 & 17.37 & $\left.13.74^{1}\right)$ & 13.46 \\
\hline 20.60 & 123.732 & 138.754 & 4.184 & 23.440 & 61.489 & 18.965 & 20.662 & 1.697 & 15.76 & 12.46 & 12.43 \\
\hline 24.90 & 123.857 & 138.769 & 4.254 & 23.401 & 62.750 & 19.321 & 20.965 & 1.643 & 14.73 & 11.65 & 11.68 \\
\hline 29.88 & 124.030 & 138.786 & 4.559 & 23.561 & 63.020 & 19.537 & 21.315 & 1.578 & 13.83 & 10.94 & 10.96 \\
\hline 34.99 & 124.236 & 138.802 & 5.304 & 24.117 & 63.460 & 20.138 & 21.675 & 1.537 & 13.12 & 10.38 & 10.36 \\
\hline 41.49 & 124.536 & 138.823 & 6.113 & 24.647 & 63.680 & 20.652 & 22.132 & 1.480 & 12.31 & 9.74 & 9.71 \\
\hline 46.79 & 124.807 & 138.841 & 6.817 & 25.099 & 63822 & 21.077 & 22.505 & 1.428 & 11.63 & 9.20 & 9.22 \\
\hline 49.89 & 124.928 & 138.851 & 7.277 & 25.438 & 63.700 & 21.321 & 22.723 & 1.402 & 11.33 & 8.96 & 8.94 \\
\hline
\end{tabular}

Volume remaining in Burette after opening first tap (corrected) $=14.8495$ at $9^{\circ} .90$ and $788,3 \mathrm{~mm}$.

$\therefore$ Volume of Spiral $=4.244$ at $9^{\circ} .90=4.243$ at $0^{\circ}=4.248$ at $50^{\circ}$.

1) This observation was rejected; it is obviously affected by some exceptional error. 
Table 2

Atmospheric Nitrogen in distilled water

Volume of bulb empty at $0^{\circ}=138.686=v_{0}$.

Volume of water taken at $0^{\circ}=125.1995=w_{0}$.

Volume of gas taken, $N_{2}$ (corrected) $=18.250 \mathrm{cc}$. at $13^{\circ} .94$ and $856.1 \mathrm{~mm}$. $=19.559$ at $0^{\circ} .760$.

Volume remaining in Burette after opening first tap (corrected) $=15.501$ at $14^{\circ} .02$ and $784.5 \mathrm{~mm}$.

$\therefore$ Volume of Spiral $=4.420$ at $14^{\circ}=4.419$ at at $0^{\circ}=4.4255$ at $50^{\circ}$.

\begin{tabular}{|c|c|c|c|c|c|c|c|c|c|c|c|c|}
\hline$t$ & $w_{t}$ & $v_{t}$ & $\left.v_{H g}{ }^{r}\right)$ & 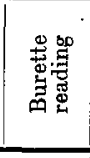 & 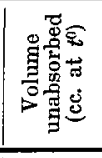 & 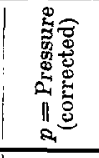 & 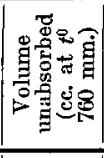 & 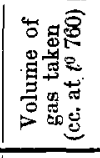 & 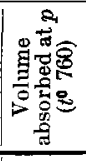 & 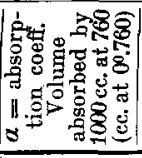 & $\begin{array}{l}\stackrel{ }{\circ} \\
\stackrel{9}{3} \\
\text { 옹 }\end{array}$ & 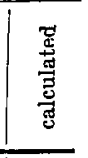 \\
\hline 0.39 & 125.213 & 138.687 & 1.556 & 3.194 & 19.531 & 66.294 & 17.037 & 19.587 & 2.550 & 23.31 & 18.44 & 18.40 \\
\hline 4.40 & 125.200 & 138.704 & 1.557 & 3.490 & 19.860 & 66.929 & 17.490 & 19.874 & 2.384 & 21.28 & 16.83 & 16.82 \\
\hline 7.40 & 125.211 & 138.711 & 1.558 & 3.708 & 20.070 & 67.457 & 17.815 & 20.089 & 2.274 & 19.92 & 15.76 & 15.79 \\
\hline 10.90 & 125.244 & 138.722 & 1.558 & 4.002 & 20.340 & 67.906 & 18.177 & 20.340 & 2.163 & 18.58 & 14.70 & 14.71 \\
\hline 12.80 & 125.271 & 138.730 & 1.559 & 3.177 & 19498 & 71.206 & 18.269 & 20.476 & 2.207 & 17.96 & 14.21 & 14.19 \\
\hline 14.25 & 125.295 & 138.733 & 1.559 & 4.195 & 20.495 & 68.614 & 18.503 & 20.580 & 2.077 & 17.45 & 13.80 & 13.82 \\
\hline 19.60 & 125.411 & 138.748 & 1.561 & 5.924 & 22.123 & 65.738 & 19.135 & 20.963 & 1.828 & 15.73 & 12.44 & 12.42 \\
\hline 23.30 & 125.517 & 138.764 & 1.561 & 4.396 & 20.504 & 71.512 & 19.293 & 21.228 & 1.935 & 15.09 & 11.94 & 11.94 \\
\hline 29.90 & 125.740 & 138.786 & 1.563 & 6.830 & 22.737 & 66.773 & 19.976 & 21.701 & 1.725 & 10.84 & 10.82 & 10.82 \\
\hline 35.76 & 125.981 & 138.805 & 1.564 & 5.635 & 21.319 & 72.581 & 20.306 & 22.121 & 1.761 & 12.95 & 10.24 & 10.28 \\
\hline 40.28 & 126.317 & 138.819 & 1.565 & 8.177 & 23.538 & 67.312 & 20.847 & 22.445 & 1.597 & 12.44 & 9.84 & 9.82 \\
\hline 45.73 & 126.470 & 138.839 & 1.566 & 6.832 & 22.059 & 72.779 & 20.167 & 22.835 & 1.668 & 11.79 & 9.33 & 9.32 \\
\hline 48.70 & 126.640 & 138.847 & 1.566 & 9.157 & 24.252 & 67.189 & 21.439 & 23.048 & 1509 & 11.44 & 9.05 & 9.05 \\
\hline 52.01 & 126.827 & 138.858 & 1.567 & 9.887 & 24.776 & 66.919 & 21.816 & 23.285 & 1.469 & 11.05 & 8.74 & 8.73 \\
\hline
\end{tabular}

1) In this experiment a small quantity of mercury was placed in the bulb before the water sample, with the object of helping mixing, in accordance with Estreicher's practice.

Table 3

Nitrogen and Sea-water

\begin{tabular}{|c|c|c|c|c|c|c|c|c|}
\hline \multicolumn{3}{|c|}{$\mathrm{Cl}=7.25$} & \multicolumn{3}{|c|}{$\mathrm{Gl}=15.32$} & \multicolumn{3}{|c|}{$\mathrm{CI}=23.41$} \\
\hline$t$ & observed & calculated & $t$ & observed & calculated & $t$ & observed & ealculated \\
\hline 0.33 & 16.88 & 16.86 & 0.61 & 15.24 & 1529 & 0.31 & 13.51 & 13.50 \\
\hline 5.81 & 15.00 & 15.03 & 6.38 & 13.50 & 1346 & 7.41 & 11.82 & 11.86 \\
\hline 13.10 & 13.16 & 13.11 & 11.91 & 12.23 & 12.22 & 11.52 & 11.15 & 11.13 \\
\hline 18.49 & 12.04 & 12.01 & 17.61 & 11.23 & 11.21 & 14.68 & 10.70 & 10.65 \\
\hline 24.11 & 11.02 & 11.09 & 22.69 & 1044 & 10.48 & 22.20 & 9.72 & 9.71 \\
\hline 27.14 & 10.69 & 10.67 & 26.55 & 10.08 & 1000 & 28.00 & 9.11 & 9.10 \\
\hline 30.59 & 10.25 & 10.25 & 29.68 & 9.60 & 9.66 & 33.08 & 8.60 & 8.61 \\
\hline
\end{tabular}

On comparing these results with those obtained by other workers in the case of distilled water, several points and interesting differences call for notice. In the case of Nitrogen the most modern determina- 
Table 4

Oxygen in distilled water

Volume of bulb empty at $0^{\circ}=138.686=v_{0}$.

Volume of water taken at $0^{\circ}=127.9645=w_{0}$.

Volume of gas taken, $O_{2}$ (corrected) $=19.370$ cc. at $5^{\circ} .40$ and $952.6 \mathrm{~mm}$. $=23.8078$ at $0^{\circ}$ and $760 \mathrm{~mm}$.

Volume remaining in Burette after opening first tap (corrected) $=16.295$ at $15^{\circ} .43$ and $903.7 \mathrm{~mm}$.

$\therefore$ Volume of Spiral $=4.8580$ at $15^{\circ} .43=4.8565$ at $0^{\circ}=4.8615$ at $50^{\circ}$.

\begin{tabular}{|c|c|c|c|c|c|c|c|c|c|c|c|}
\hline$t$ & $w_{t}$ & $v_{t}$ & 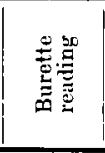 & 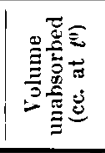 & 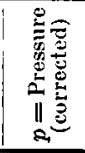 & 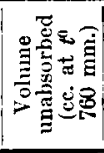 & 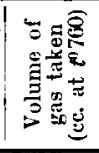 & 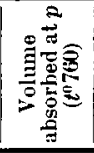 & 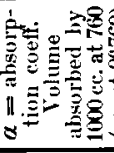 & 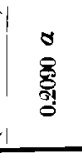 & 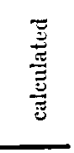 \\
\hline 0.61 & 127.976 & 138.689 & 2.973 & 18541 & 73.57 & 17.824 & 23.861 & 6037 & 48.61 & 10.16 & 10.13 \\
\hline 0.81 & 127.975 & 138.690 & 6.142 & 22.713 & 62.80 & 18.768 & 23.878 & 5.110 & 48.18 & 10.07 & 10.08 \\
\hline 5.51 & 127.967 & 138.705 & 3.953 & 19.559 & 73.51 & 18.911 & 24.288 & 5.377 & 4258 & 8.90 & 892 \\
\hline 5.60 & 127.967 & 138.707 & 11.285 & 26.882 & 56.95 & 20.144 & 24.296 & 4.152 & 42.58 & 8.90 & 8.90 \\
\hline 10.82 & 128.009 & 138.722 & 8.018 & 23.578 & 6577 & 20.404 & 24.751 & 4.347 & 37.75 & 7.87 & 7.88 \\
\hline 10.90 & 128.014 & 138.723 & 3.983 & 19.559 & 76.54 & 19.698 & 24.758 & 5.060 & 37.76 & 7.89 & 7.86 \\
\hline 15.60 & 128.088 & 138.739 & 7.467 & 23.075 & 69.12 & 20.986 & 25.168 & 4.182 & 33.97 & 7.10 & 7.14 \\
\hline 15.60 & 128.088 & 138739 & 4.578 & 20.086 & 77.54 & 20.443 & 25.168 & 4.725 & 34.21 & 7.15 & 7.14 \\
\hline 20.80 & 128.213 & 138.755 & 5.242 & 20.643 & 7812 & 21.219 & 25.622 & 4.403 & 31.05 & 6.49 & 6.48 \\
\hline 20.81 & 128.213 & 138.755 & 9.160 & 24.611 & 67.44 & 21.839 & 25623 & 3.784 & 3091 & 6.46 & 6.48 \\
\hline 26.00 & 128.375 & 138.773 & 5.933 & 21.204 & 78.62 & 21.935 & 26.075 & 4.140 & 28.47 & 5.95 & 5.94 \\
\hline 26.00 & 128.375 & 138.773 & 10.416 & 25.673 & 66.76 & 22.553 & 26.075 & 3.522 & 28.52 & 5.96 & 5.94 \\
\hline 30.98 & 128.560 & 138.789 & 10.425 & 25.513 & 69.16 & 23.227 & 26.509 & 3.282 & 25.19 & 5.26 & 5.26 \\
\hline 31.04 & 128.562 & 138.790 & \begin{tabular}{|l|}
6359 \\
\end{tabular} & 21.446 & 80.43 & 22.696 & 26515 & 3.819 & 25.17 & 5.26 & 5.26 \\
\hline 35.49 & 128.752 & 138.804 & 6.851 & 21.763 & 80.66 & 23.098 & 26.903 & 3.805 & 24.65 & 5.15 & 5.16 \\
\hline 35.59 & 128.756 & 138.805 & 11.231 & 26.140 & 68.80 & 23.664 & 26.911 & 3.247 & 24.66 & 5.15 & 5.15 \\
\hline 40.04 & 128.966 & 138.818 & 11.228 & 25.930 & 70.62 & 24.095 & 27.299 & 3.204 & 23.32 & 4.87 & 4.87 \\
\hline 40.09 & 128970 & 138.819 & 7.127 & 21.936 & 81.76 & 23.598 & 27.304 & 3.706 & 23.30 & 4.87 & 4.86 \\
\hline 45.29 & 129.242 & 138.836 & 11.416 & 25.871 & 72.30 & 24.611 & 27.757 & 3.146 & 21.95 & 4.59 & 4.58 \\
\hline 45.29 & 129.242 & 138.836 & 7.697 & 22.151 & 82.89 & 24.159 & 27.757 & 3.598 & 21.90 & 4.58 & 4.58 \\
\hline 50.25 & 129.523 & 138.852 & 7.116 & 22.307 & 83.99 & 24.652 & 28.190 & 3.538 & 20.88 & 4.36 & 4.37 \\
\hline 50.29 & 129.527 & 138.854 & 11.806 & 26.094 & 73.14 & 25.112 & 28.193 & 3.081 & 20.88 & 4.36 & 4.37 \\
\hline
\end{tabular}

tions are those of WINKLER $^{1}$ ) and of BoHR and Bock ${ }^{2}$ ) both of them evidently carried out with the utmost refinement and precision. There are several older determinations, good in their day but made by less perfect methods; omitting those of Bunsen which now only have historic value, those of DitTMar $^{3}$ ), TORNöE ${ }^{4}$ ), HaMBerg ${ }^{5}$ ) and of Pettersson and Sønden ${ }^{6}$ ) may be mentioned. On comparing all these

1) Berichte d. Deutschen Chemischen Gesellschaft 22. (1889). 1766.

2) Wiedemann's Annalen 44. (1891). 316.

3). Challenger Expedition. Physics and Chemistry. Vol. 1, p. 172.

4) Den norske Nordhavs Expedition. 1876-1878. Chemistry.

$\left.{ }^{5}\right)$ Bihang til K. Svenska Vet. Akad. Handlinger 10. No. 13. 1885.

6) Svensk kemisk Tidskrift. 1889, p. 17. 


\section{Table 5}

Oxygen in distilled water

Volume of bulb empty at $0^{\circ}=138.2724=v_{0}$.

Volume of water taken at $0^{\circ}=127.4260=w_{0}$.

Volume of gas taken, $O_{2}$ (corrected) $=19.965$ cc. at $16^{\circ} .40$ and $978.15 \mathrm{~mm}$.

$=25.1071$ at $0^{\circ}$ and $760 \mathrm{~mm}$.

Volume remaining in Burette after opening first tap (corrected) $=16.615$ at 16.54 and $900.6 \mathrm{rnm}$.

$\therefore$ Volume of Spiral $=6.060$ at $16^{\circ} .54=5.058$ at $0^{\circ}=5.062$ at $45^{\circ}$.

\begin{tabular}{|c|c|c|c|c|c|c|c|c|c|c|c|}
\hline$t$ & $w_{t}$ & $v_{t}$ & 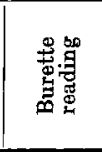 & 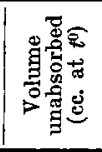 & 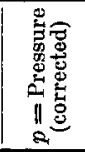 & 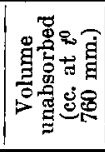 & 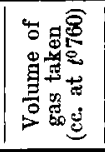 & 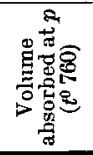 & 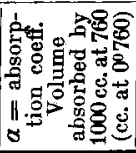 & 离 & 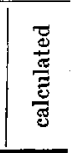 \\
\hline 1.63 & 127.432 & 138.278 & 3.930 & 19.834 & 74.34 & 19.329 & 25.257 & 5.928 & 47.27 & 9.88 & 9.85 \\
\hline 2.18 & 127.429 & 138.281 & 8.162 & 24071 & 64.06 & 20.289 & 25.308 & 5.019 & 46.36 & 9.69 & 9.71 \\
\hline 6.20 & 127.430 & 138.293 & 4.468 & 20.390 & 75.50 & 20.256 & 25.677 & 5.421 & 41.87 & 875 & 8.76 \\
\hline 6.60 & 127.433 & 138.297 & 8.771 & 24.694 & 64.88 & 21.081 & 25.714 & 4.633 & 41.58 & 8.69 & 8.68 \\
\hline 9.53 & 127.456 & 138.304 & 4.766 & 20.673 & 76.58 & 20.831 & 25.983 & 5.152 & 38.76 & 8.10 & 8.11 \\
\hline 9.61 & 127.457 & 138.306 & 9.084 & 24.992 & 65.61 & 21.576 & 25.991 & 4.415 & 38.76 & 8.10 & 8.10 \\
\hline 13.65 & 127.513 & 138.318 & 8.086 & 24.951 & 67.45 & 22.144 & 26.362 & 4.218 & 35.50 & 7.42 & 7.42 \\
\hline 13.75 & 127.515 & 138.319 & 6.040 & 21.904 & 78.09 & 22.506 & 26.372 & 4.866 & 35.36 & 7.39 & 7.41 \\
\hline 16.72 & 127.573 & 138.328 & 5.750 & 21.565 & 7761 & 22.022 & 26.645 & 4.623 & 33.44 & 6.99 & 6.98 \\
\hline 16.75 & 127.573 & 138.329 & 10.111 & 25.927 & 66.54 & 22.700 & 26.647 & 3.947 & 33.30 & 6.96 & 698 \\
\hline 23.80 & 127.762 & 138.351 & 6.125 & 21775 & 80.11 & 22.953 & 27.296 & 4.343 & 29.67 & 6.20 & 6.16 \\
\hline 23.90 & 127.765 & 138.353 & 10.569 & 26.217 & 68.43 & 23.606 & 27.305 & 3.699 & 29.57 & 6.18 & 6.15 \\
\hline 29.86 & 127.974 & 138.372 & 11.184 & 26.643 & 69.62 & 24.406 & 27.853 & 3.447 & 26.51 & 5.54 & 5.58 \\
\hline 29.88 & 127.975 & 138.373 & 7.204 & 22.763 & 79.74 & 23.883 & 27.855 & 3.962 & 26.60 & 5.56 & 5.58 \\
\hline 37.51 & 128.303 & 138.397 & 11.572 & 26.738 & 71.74 & 25.239 & 28.587 & 3.318 & 24.09 & 5.03 & 5.03 \\
\hline 37.54 & 128.304 & 138398 & 7.553 & 22.719 & 82.23 & 24.761 & 28.559 & 3.798 & 24.06 & 5.03 & 5.03 \\
\hline 43.25 & 128.587 & 138.466 & 8.188 & 23.129 & 83.52 & 25.418 & 29.085 & 3.667 & 22.41 & 4.68 & 4.69 \\
\hline 43.29 & 128.591 & 138.467 & 12.395 & 27.534 & 71.59 & 25.936 & 29.088 & 3.152 & 22.40 & 4.68 & 4.68 \\
\hline
\end{tabular}

Table 6

Oxygen and Sea-water

\begin{tabular}{|c|c|c|c|c|c|c|c|c|}
\hline \multicolumn{3}{|c|}{$\mathrm{Cl}=7.68$} & \multicolumn{3}{|c|}{$\mathrm{Gl}=14.27$} & \multicolumn{3}{|c|}{$\mathrm{Gl}=20.31$} \\
\hline$t$ & observed & calculated & $t$ & observed & calculated & $t$ & observed & calculated \\
\hline 0.32 & 9.36 & 9.32 & 044 & 8.50 & 8.54 & 0.47 & 7.89 & 7.84 \\
\hline 4.96 & 8.09 & 8.07 & 5.32 & 7.53 & 7.57 & 6.10 & 6.81 & 6.86 \\
\hline 12.22 & 7.00 & 7.04 & 11.98 & 6.60 & 6.56 & 12.03 & 6.02 & 6.08 \\
\hline 16.36 & 6.46 & 6.50 & 14.36 & 6.28 & 6.28 & 14.89 & 5.84 & 5.78 \\
\hline 21.22 & 5.93 & 5.96 & 20.10 & 570 & 5.66 & 19.86 & 5.33 & 5.30 \\
\hline 26.84 & 5.56 & 5.52 & 25.31 & 5.22 & 5.19 & 26.02 & 4.75 & 4.78 \\
\hline 30.22 & 5.13 & 5.13 & 30.66 & 4.76 & 4.72 & 31.02 & 435 & 4.36 \\
\hline
\end{tabular}

investigators results and it is noticed firstly that WINkLER's and BoHR and Bock's values are appreciably lower than the older values obtained 
by former workers. Then again WINKLER's values are appreciably lower than BoHr and Bock's. The present writer's values lie between those of WINkLER and of BoHR and Bock. On comparing the methods employed by the different workers it must be noted that all of the older methods mentioned, were carried out by bubbling air through the water and then extracting the air and measuring the volume. This method has the advantage that it is strictly analogous to the action between sea-water and the Atmosphere in Nature; the chief disadvantage is that it is not easy to tell when exact equilibrium is reached. In any case the gas-phase as well as the liquid-phase really ought to be analysed whenever this kind of method is employed. BoHr and Bock also used the same method but with greater refinement and precision. On the other hand the values of WINkLER and the present writer were obtained by shaking the gas with the liquid and then measuring the contraction; in effect an analysis of the gaseous-phase, while the other method may be regarded as an analysis of the liquid-phase. If only pure gases are concerned, both methods may be expected to give the same result under good conditions; and in this connection it may be noticed that all methods tend in the case of Oxygen to give more concordant values than in the case of Nitrogen. And the reason for the difference in the latter case is to be sought in the fact that Atmospheric-Nitrogen is not a pure substance but contains $1.185 \%$ of Argon ${ }^{1}$ ), the solubility of which is more than double that of Nitrogen at $0^{\circ}$ and which falls off with the temperature at a different rate. Unfortunately it is not possible to tell from the accounts accessible to the present writer, whether WinkLeR's Nitrogen was chemically prepared or obtzined from the Atmosphere.

In the case of determinations made by the method adopted also by Boнr and Bock, it is clear that both the Nitrogen and Argon always have at all temperatures the partial pressure they have in the open air. On the other hand in the absorption methods employed by WINKLER and the present writer, the amounts of Nitrogen and Argon actually dissolved in the liquid-phase at different temperatures is different and varies differently with the temperature. The result is that by these methods the percentage of each left over in the gaseousphase will also be different at different temperatures, by a corresponding amount; and the partial pressures to that extent different for different temperatures, instead of constant and the same as that of the air, as in BoHR and Bock's method. The writer only noticed this point after having calculated the formula from his observations and upon then comparing the results with those found by the other investigators ${ }^{2}$ ).

1) Tpavers loc. cit. p. 116.

2) Dr. Ersst Ruppin, Kiel has noticed this point too and was also kind enough to call the writer's attention to it by letter. 
The differences may be represented by the following formula for Atmospheric-Nitrogen of partial pressure 0.7910 of an atmosphere.

$$
x=\frac{0.7910 \times 1.185}{100}\left(\alpha_{1}-\alpha_{2}\right)=0.009373\left(\alpha_{1}-\alpha_{2}\right)
$$

Where $x$ represents the no. of cc. to be added to the value obtained by the method employed by the writer, to make it comparable with that employed by BoHr and Bock, in which the Nitrogen always at all temperatures has a constant partial pressure of 0.7816 and Argon a constant partial pressure of 0.0094 of an atmosphere. $\alpha_{1}$ and $\alpha_{2}$ are the absorption coefficients concerned, of Argon and of Atmospheric-Nitrogen respectively. Those for Argon have been determined by Estreicher by the same method as used by the present writer. This correction was calculated for every degree; it was found to be $0.322 \%$ at $0^{\circ}, 0.239$ at $10^{\circ}, 0.197$ at $20^{\circ}$ and 0.169 at $30^{\circ}$. This correction is also included in Tables 8 and 11.

In Table 7 are to be found values for Atmospheric-Nitrogen, according to determinations of WINKLER and the writer, corrected and uncorrected by this amount, required to make the values correspond to a constant partial pressure of pure Nitrogen equal to 0.7816 of an atmosphere plus a constant partial pressure of Argon equal to 0.0094 of an atmosphere; the two together making up a constant Atmospheric-Nitrogen partial pressure equal to 0.7910 of an atmosphere. As stated already, there is in view of the fact that it is unknown how the Nitrogen was prepared, no difinitely satisfactory reason for applying this particular correction to WINKLER's determinations; the Nitrogen used by him may very well have been prepared chemically and therefore quite free from Argon. In that case the true correction necessary would of course be even larger, but only by $0.04 \mathrm{cc}$. "/00; and this is of no importance. There is therefore sufficient reason for including in the 'Table, WINKLER's determinations with the given correction added.

Table 7

Solubilities in distilled water of Atmospherje Nitrogen (Nitrogen, 0.7816 atmosphere + Argon, 0.0094 atmosphere)

\begin{tabular}{|c|c|c|c|c|c|c|c|}
\hline \multirow{2}{*}{$t$} & \multicolumn{2}{|c|}{ Winkler } & \multirow{2}{*}{$\begin{array}{c}\text { Bohr \& } \\
\text { Bock }\end{array}$} & \multicolumn{2}{|c|}{ Fox } & \multirow{2}{*}{ Hamberg } & \multirow{2}{*}{ Dittmar } \\
\hline & uncorrected & corrected & & uncorrected & corrected & & \\
\hline 0 & 18.57 & 18.89 & 18.89 & 18.56 & 18.88 & 19.14 & 19.30 \\
\hline 5 & 16.46 & 16.73 & 17.03 & 16.60 & 1687 & 16.93 & 17.10 \\
\hline 10 & 14.69 & 14.93 & 15.47 & 14.97 & 15.21 & 15.14 & 15.37 \\
\hline 15 & 13.30 & 13.51 & 14.13 & 13.63 & 13.84 & 13.73 & 13.96 \\
\hline 20 & 12.20 & 12.40 & 12.97 & 12.54 & 12.74 & 12.63 & 12.81 \\
\hline 25 & 11.32 & 1150 & 11.90 & 1166 & 11.84 & 1181 & 11.83 \\
\hline 30 & 10.60 & 10.77 & 10.92 & 10.94 & 11.11 & - & 10.99 \\
\hline
\end{tabular}


It then appears that the values of the writer lie between those of BoHr and Bock and Hamberg and that all of them are very near to one another. WinkLen's and DirTman's also are not much different; the former's agree especially well at the lower temperatures the latter's at the higher temperatures. An inspection of all of them together, makes it seem probable that the absorption coefficients in distilled water may be regarded now as very well known, probably correct to $0.1 \mathrm{cc} \%$ Absolute.

In the case of sea-water the coefficients hitherto in use are those of HaMBERG, whose table has been doing excellent service in Oceanography since its publication in $1885^{1}$ ).

Dítmar and Tornös had also both made determinations before, but without determining the Chlorine of their samples; they are for this reason of no value.

Table 8 contains a comparison of the values found by HAMBERG and the present writer for waters of Chlorine equal to 5.52, 11.06, 16.60 and $19.38 \%$ (Hamberg's Salinities of $10,20,30,35 \%$ ). It will

Tahle 8

\begin{tabular}{|c|c|c|c|c|c|c|c|c|}
\hline \multirow{2}{*}{$t$} & \multicolumn{2}{|c|}{$\mathrm{Gl}=5.52$} & \multicolumn{2}{|c|}{11.06} & \multicolumn{2}{|c|}{16.60} & \multicolumn{2}{|c|}{19.38} \\
\hline & Hamberg & Fox & Hamberg & Fux & Hamberg & Fux & Hambery & Fox \\
\hline 0 & 17.71 & 17.71 & 16.45 & 16.52 & 15.34 & 15.31 & 14.85 & $14.6 \tilde{j}$ \\
\hline 5 & 15.76 & 15.69 & 14.70 & 14.87 & 13.75 & 13.84 & 13.32 & 13.31 \\
\hline 10 & 14.16 & 14.21 & 13.26 & 13.53 & 12.44 & 12.67 & 12.06 & 12.20 \\
\hline 15 & 12.88 & 13.00 & 12.10 & 12.42 & 11.38 & 11.68 & $11 .(4$ & 11.29 \\
\hline 20 & 11.87 & 12.02 & 11.17 & 11.53 & 10.54 & 10.90 & 10.25 & 10.56 \\
\hline 25 & 11.09 & 11.21 & 10.45 & 10.78 & 9.88 & 10.23 & 9.62 & 9.93 \\
\hline
\end{tabular}

be seen that the agreement is on the whole very good, especially for low temperatures and low salinities. Hamberg's salinities are no doubt rather uncertain, when compared with modern work.

Table 9

\begin{tabular}{r||c|c|c|c|c}
\hline & Winkler & Dittmar & Bohr \& Bock & Jakobsen & Fox \\
\hline 0 & 10.25 & 10.25 & 10.32 & 10.06 & 10.29 \\
5 & 8.98 & 8.99 & 9.14 & 8.80 & 9.03 \\
10 & 7.97 & 8.00 & 8.11 & 7.79 & 8.02 \\
15 & 7.16 & 720 & 7.28 & 7.01 & $7.2 \%$ \\
20 & 6.50 & 6.53 & 6.59 & 6.39 & 6.57 \\
25 & 5.96 & 5.97 & 6.04 & 5.89 & 6.04
\end{tabular}

1) loc. cit. 
GHAS. J. J. FOX

Tabl

No. of cc. of Nitrogen (including Argon) absorbed by $1000 \mathrm{ct}$

\begin{tabular}{|c|c|c|c|c|c|c|c|c|c|c|}
\hline$t$ & $\mathrm{Cl}=0$ & $\mathrm{Cl}=1$ & $\mathrm{Cl}=2$ & $\mathrm{Gl}=3$ & $\mathrm{cl}=4$ & $\mathrm{Cl}=5$ & $\mathrm{Cl}=6$ & $\mathrm{Cl}=7$ & $\mathrm{Gl}=8$ & $\mathrm{Cl}=9$ \\
\hline-2 & $\begin{array}{l}19.79 \\
19.33\end{array}$ & $\begin{array}{l}19.56 \\
19.10\end{array}$ & $\begin{array}{l}19.33 \\
18.88\end{array}$ & $\begin{array}{l}19.10 \\
18.66\end{array}$ & $\begin{array}{l}18.87 \\
18.44\end{array}$ & $\begin{array}{l}18.64 \\
18.22\end{array}$ & $\begin{array}{l}18.41 \\
17.99\end{array}$ & $\begin{array}{l}18.18 \\
17.77\end{array}$ & $\begin{array}{l}17.95 \\
17.55\end{array}$ & 17.72 \\
\hline 0 & 18.88 & 18.67 & 18.45 & 18.24 & 18.02 & 17.81 & 17.59 & 17.38 & 17.16 & $16.9^{\circ}$ \\
\hline 1 & 18.45 & 18.24 & 18.03 & & 17.62 & 17.41 & 17.20 & 16.99 & 16.78 & $\begin{array}{l}10.50 \\
16.58\end{array}$ \\
\hline 2 & 18.03 & 17.83 & 17.63 & 17.43 & 17.23 & 17.03 & 16.83 & 16.63 & 16.42 & 16.22 \\
\hline 3 & 17.63 & 17.44 & 17.24 & 17.05 & 16.85 & 16.66 & 16.47 & 16.27 & 16. & 15.88 \\
\hline 4 & 17.24 . & 17.06 & 16.87 & 16.68 & 16.49 & 16.31 & 16.12 & 15.93 & 15.74 & 15.55 \\
\hline 5 & 16.87 & 16.69 & 16.51 & 16.32 & 16.14 & 1596 & 15.78 & 15.60 & 15.42 & 15.23 \\
\hline 6 & 16.51 & 16.33 & 16.16 & 15. & 15.81 & 15 & 15.45 & 15.28 & 1510 & 14.93 \\
\hline 7 & 16.17 & 16.0 & 15. & 15.66 & 15.49 & 15 & 15.15 & 14. & 14. & 14.64 \\
\hline 8 & 15.84 & 15.67 & 15.51 & 15.34 & 15.18 & 15.02 & 14.85 & 1469 & 14.52 & 14.36 \\
\hline 9 & 15.52 & 15.35 & 15.20 & 15.04 & 14.88 & 14.72 & 14.56 & 14.40 & 1424 & 14.09 \\
\hline 10 & 15.21 & 15.05 & 14.91 & 14.75 & 14.60 & 14.44 & 14.29 & 14.13 & 13.98 & 13.83 \\
\hline 11 & 14.92 & 14.76 & 14. & 14.47 & 14. & 14. & 14. & 13. & 13 & 1358 \\
\hline 12 & 14.64 & 14.49 & 14.35 & 14.20 & 14.06 & 13.91 & 13.77 & 13. & 13.48 & 1334 \\
\hline 13 & 14.36 & 14.22 & 14.08 & 13.94 & 13.8 & 13.66 & 13.52 & 13.39 & 13.25 & 13.11 \\
\hline 14 & 14.10 & 13.96 & 13.83 & 13.70 & 13.56 & 13.42 & 13.29 & 1316 & 13.03 & 12.89 \\
\hline 15 & 13.84 & 13.71 & 13.58 & 13.45 & 13.32 & 13.19 & 13.06 & 12.94 & 12.81 & 12.68 \\
\hline 16 & 13.61 & 13.48 & 13.35 & 13.23 & 13. & 12. & 12.8 & 12.7 & 12.60 & 12.48 \\
\hline 17 & 13.38 & 13.25 & 13.13 & 13.01 & 12.8 & 12. & 126 & & & 12.28 \\
\hline 18 & 13.1 & 13.03 & 12.92 & 12.80 & 1268 & 12.56 & 12.44 & 12.33 & 12.21 & 12.09 \\
\hline 19 & 12.94 & 12.83 & 12.71 & 12.60 & 12.49 & 12.37 & 12.26 & 12.14 & 12.03 & 11.91 \\
\hline 20 & 1274 & & & & & & 12.08 & 11.96 & 11.85 & 11.74 \\
\hline 21 & 12.54 & & & 12. & & 12. & 11. & 11.2 & 11. & 11.57 \\
\hline 22 & 12.8 & 12. & 12. & 12. & & 11. & 11. & 11. & 11.52 & 11.41 \\
\hline 23 & 12.18 & 12. & 11.97 & 11.8 & & 11. & & 11. & 11. & 11.26 \\
\hline 24 & 12.00 & 11.90 & 11.80 & 11.70 & 11.60 & 11.51 & 11.41 & 11.31 & 11.21 & 11.11 \\
\hline 25 & 11.8 & 11.74 & 11.65 & 11.5 & 11.4 & 11.3 & 11.2 & 11.16 & 11.07 & 10.97 \\
\hline 26 & 11.68 & & 11.5 & & 11. & & & & 10.93 & 10.83 \\
\hline 27 & & & & & & & & & 10. & 10.70 \\
\hline 28 & & & 11.20 & 11.11 & 11.02 & 10.93 & 10.84 & 10.75 & 10.66 & 10.57 \\
\hline 29 & 11.24 & 11.15 & 11.07 & 10.98 & 10.89 & 10.80 & 1072 & 10.63 & 10.54 & 10.45 \\
\hline 30 & 11.11 & 11.03 & 10.94 & 10.85 & 10.76 & 10.68 & 10.60 & 10.51 & 10.42 & 10.34 \\
\hline
\end{tabular}

In the case of the Oxygen the presence or absence of Argon has never had any influence upon older determination. For this reason perhaps, the values of different investigators have shown better agreement with one another than was the case with Nitrogen. Table 9 contains values for Oxygen, of partial pressure 0.2090 of an atmosphere, in distilled water, obtained in the most modern investigations. 
[ata-water from a free dry Atmosphere of 760 mm. pressure

\begin{tabular}{|c|c|c|c|c|c|c|c|c|c|c|}
\hline$=10$ & $\mathrm{Cl}=1 \mathrm{I}$ & $\mathrm{Gl}=12$ & $\mathrm{Cl}=13$ & $\mathrm{Cl}=14$ & $\mathrm{Cl}=15$ & $\mathrm{Cl}=16$ & $\mathrm{CI}=17$ & $\mathrm{Cl}=18$ & $\mathrm{Cl}=19$ & $\mathrm{Cl}=20$ \\
\hline 17.49 & 17.26 & 17.03 & 16.80 & 16.57 & 16.34 & 16.11 & 15.89 & 15.66 & 15.43 & 15.20 \\
\hline 17.11 & 16.88 & 16.66 & 16.44 & 16.22 & 16.00 & 15.77 & 15.55 & 15.33 & 15.11 & 14.88 \\
\hline 16.73 & 1652 & 16.30 & 16.09 & 15.87 & 15.66 & 15.44 & 1523 & 15.01 & 14.80 & 14.58 \\
\hline 16.37 & 16.16 & 15.95 & 15.75 & 15.64 & 15.33 & 15.12 & 14.92 & 14.71 & 14.50 & 1429 \\
\hline 16.02 & 15.82 & 15.62 & 15.42 & 15.22 & 15.02 & 14.82 & 14.61 & 14.41 & 14.21 & 14.01 \\
\hline 15.69 & 15.49 & 1530 & 15.11 & 14.91 & 14.72 & 14.52 & 14.33 & 14.13 & 1394 & 13.74 \\
\hline 15.37 & 15.18 & 14.99 & 14.80 & 14.61 & 14.43 & 14.24 & 1405 & 13.86 & 13.67 & 13.49 \\
\hline 6.05 & 14.87 & 1469 & 14.51 & 14.33 & 14.14 & 13.96 & 13.78 & 13.60 & 13.42 & 13.24 \\
\hline 14.76 & 14.58 & 14.40 & 14.23 & 14.05 & 13.87 & 13.70 & 13.52 & 13.35 & 13.17 & 13.00 \\
\hline 14.47 & 14.30 & 14.13 & 13.96 & 13.79 & 13.62 & 13.45 & 13.28 & 13.11 & 1294 & 12.77 \\
\hline 14.19 & 14.03 & 13.87 & 13.70 & 13.54 & 13.37 & 13.21 & 13.05 & 12.88 & 12.72 & 12.55 \\
\hline [3.93 & 13.77 & 13.61 & 1345 & 13.29 & 13.13 & 12.98 & 12.82 & 12.66 & 12.50 & 12.34 \\
\hline 13.68 & 13.53 & 13.37 & 13.22 & 13.06 & 12.91 & 12.76 & 12.61 & 12.45 & 12.30 & 12.15 \\
\hline 3.43 & 13.28 & 13.13 & 12.99 & 12.84 & 12.69 & 12.54 & 12.39 & 12.25 & 12.10 & 11.95 \\
\hline .320 & 13.05 & 12.91 & 12.77 & 1262 & 12.48 & 12.34 & 1219 & 12.05 & 11.91 & 11.76 \\
\hline 2.97 & 12.83 & 12.69 & 12.56 & 12.42 & 12.28 & 12.14 & 12.00 & 11.86 & 11.72 & 11.58 \\
\hline 2.76 & 12.63 & 12.49 & 1236 & 12.22 & 12.09 & 11.96 & 11.82 & 11.68 & 11.55 & 11.42 \\
\hline 255 & 12.42 & 12.29 & 12.16 & 12.03 & 11.90 & 11.77 & 11.64 & 11.51 & 11.38 & 11.25 \\
\hline 2.35 & 12.23 & 1210 & 1198 & 11.85 & 11.73 & 11.60 & 11.47 & 11.35 & 11.22 & 11.10 \\
\hline 2.16 & 12.04 & 11.92 & 11.80 & 11.67 & 11.56 & 11.44 & 11. & 11.19 & 11.07 & 10.95 \\
\hline .97 & 11.86 & 11.74 & 11.62 & 11.50 & 11.39 & 11.27 & 11. & 11.03 & 10.92 & 10.80 \\
\hline 1.80 & 1169 & 11.57 & 11.46 & 11.34 & 11.23 & 11.12 & 11.00 & 10.89 & 10.78 & 10.66 \\
\hline l.63 & 11.53 & 11.41 & & 11.18 & & 10.97 & 10. & 10.75 & 10.64 & 10.52 \\
\hline 1.47 & 1136 & 11.25 & 11.14 & 11.03 & 10.93 & 10.83 & 10.72 & 10.61 & 10.50 & 10.39 \\
\hline l.31 & 1.21 & 11.10 & 11.00 & 10.89 & 10.79 & 10.69 & 10.59 & 10.48 & 10.37 & 10.26 \\
\hline L.16 & 11.06 & 10.95 & 10.86 & 10.75 & 10.65 & 10.56 & 10.46 & 10.35 & 10.24 & 10.14 \\
\hline l.01 & 10.91 & 10.81 & 10.72 & 10.62 & 10.52 & 10.43 & 10.33 & 10.22 & 10.12 & 10.02 \\
\hline 1.87 & & & & & & & & 10.10 & 10.00 & 9.90 \\
\hline 1.74 & 10.65 & 10.55 & 10.46 & 10.36 & 10.27 & 10.18 & 10.08 & 9.98 & 9.88 & 9.79 \\
\hline 1.61 & 10.52 & 10.42 & 10.33 & 10.24 & 10.15 & 10.06 & 9.97 & 9.87 & 9.77 & 9.68 \\
\hline 1.48 & $10: 39$ & 10.30 & 10.21 & 10.12 & 10.03 & 9.94 & 985 & 9.76 & 9.66 & 9.57 \\
\hline 1.36 & 10.27 & 10.18 & 10.10 & 10.01 & 9.92 & 9.83 & 9.74 & 9.65 & 9.56 & 9.47 \\
\hline 1.25 & 10.16 & 10.08 & 9.99 & 9.90 & 9.82 & 9.73 & 9.64 & 9.56 & 9.47 & 9.38 \\
\hline
\end{tabular}

The only one that differs appreciably from the others is the most modern one of all, that of $\left.\mathrm{J}_{\mathrm{ACOBSEN}}{ }^{2}\right)$. $\mathrm{He}$, in his determination, placed a quantity of water in a large bottle and rotated it, by means of a motor, with its axis horizontal, until determination by means of the

2) J. P. JACoBsaN, Meddelelser fra Kommissionen for Havundersøgelser. Serie: Hydrografi. Bind 1, No. 8. Kopenhagen, 1905. 
CHAS. J. J. FOX

Tabl)

No of cc. of Oxygen absorbed by 1000 cc. of sea-watel

\begin{tabular}{|c|c|c|c|c|c|c|c|c|c|c|}
\hline$t$ & $\mathrm{Cl}=0$ & $\mathrm{Cl}=1$ & $\mathrm{Cl}=2$ & $\mathrm{Cl}=3$ & $\mathrm{CI}=4$ & $\mathrm{Gl}=5$ & $\mathrm{Cl}=6$ & $\mathrm{Cl}=7$ & $\mathrm{Cl}=8$ & $\mathrm{Cl}=9$ \\
\hline-2 & 10.88 & 10.75 & 10.63 & 10.50 & 10.38 & 10.26 & 10.13 & 10.01 & 9.88 & 9.76 \\
\hline-1 & 10.58 & 10.46 & 10.34 & 10.22 & 10.10 & 9.98 & 9.86 & 9.74 & 9.62 & 9.50 \\
\hline 0 & 10.29 & 10.17 & 10.06 & 994 & 9.83 & 9.71 & 9.59 & 9.48 & 9.36 & 9.25 \\
\hline 1 & 10.02 & 9.90 & 9.79 & 9.68 & 9.57 & 9.45 & 934 & 9.23 & 9.12 & 9.01 \\
\hline 2 & 9.75 & 9.64 & 953 & 9.43 & 9.32 & 9.21 & 9.10 & 8.99 & 8.88 & 8.78 \\
\hline 3 & 9.50 & 9.39 & 9.29 & 9.19 & 9.08 & 8.98 & 8.87 & 8.77 & 8.66 & 8.56 \\
\hline 4 & 9.26 & 9.16 & 9.06 & 8.95 & 8.85 & 8.75 & 8.65 & 8.55 & 8.45 & 8.35 \\
\hline 5 & 903 & 893 & 8.83 & 8.73 & 8.64 & 8.54 & 8.44 & 8.34 & 8.24 & 8.14 \\
\hline 6 & 8.81 & 8.71 & 8.62 & 8.52 & 8.43 & 8.33 & 8.24 & 8.14 & 8.05 & 7.95 \\
\hline 7 & 8.60 & 8.50 & 8.41 & 8.32 & 8.23 & 8.14 & 8.04 & 7.95 & 7.86 & 7.77 \\
\hline 8 & 8.40 & 8.31 & 8.22 & 8.13 & 8.04 & 7.95 & 7.86 & 7.77 & 7.68 & 7.59 \\
\hline 9 & 8.21 & 8.12 & 8.03 & 7.95 & 7.86 & 777 & 7.69 & 7.60 & 7.52 & 7.43 \\
\hline 10 & 8.02 & 7.94 & 7.85 & 7.77 & 7.69 & 7.60 & $7 . \tilde{2} 2$ & 7.44 & 7.36 & 7.27 \\
\hline 11 & 7.84 & 7.76 & 7.68 & 7.60 & 7.52 & 7.44 & 7.36 & 7.28 & 7.20 & 7.12 \\
\hline 12 & 7.68 & 7.60 & 7.52 & 7.44 & 7.36 & 7.29 & 721 & 7.13 & 7.05 & 6.97 \\
\hline 13 & 7.52 & 7.44 & 7.36 & 7.29 & 7.21 & 7.14 & 7.06 & 6.98 & 6.91 & 6.83 \\
\hline 14 & 7.37 & 7.29 & 7.21 & 7.14 & 7.07 & 7.00 & 6.92 & 6.85 & 6.77 & 6.70 \\
\hline 15 & 7.22 & 715 & 7.07 & 7.00 & 6.93 & 6.86 & 6.79 & 6.72 & 6.64 & 6.57 \\
\hline 16 & 7.08 & 7.01 & 6.94 & 6.87 & 6.80 & 6.73 & 6.66 & 6.59 & 6.52 & 6.45 \\
\hline 17 & 6.94 & 6.88 & 6.81 & 674 & 6.67 & 6.60 & 6.54 & 6.47 & 6.40 & 6.33 \\
\hline 18 & 6.81 & 6.75 & 6.68 & 6.62 & 6.55 & 6.48 & 6.42 & 6.35 & 6.28 & 6.22 \\
\hline 19 & 6.69 & 6.63 & 6.56 & 6.50 & 6.44 & 6.37 & 6.30 & 6.24 & 6.17 & 6.11 \\
\hline 20 & 6.57 & 6.51 & 6.44 & 6.38 & 6.33 & 6.26 & 6.19 & 6.13 & 6.07 & 6.00 \\
\hline 21 & 646 & 6.40 & 6.33 & 6.27 & 6.22 & 6.15 & 609 & 6.03 & 5.96 & 5.90 \\
\hline 22 & 6.35 & 6.29 & 6.23 & 6.17 & 6.11 & 6.04 & 5.98 & 5.92 & 5.86 & 5.80 \\
\hline 23 & 6.24 & 6.18 & 6.12 & 6.06 & 6.01 & 5.94 & 5.88 & 5.82 & 5.77 & 5.71 \\
\hline 24 & 6.14 & 6.08 & 6.02 & 5.97 & 5.91 & 5.84 & 5.79 & 5.73 & 5.67 & 5.61 \\
\hline 25 & 6.04 & 5.99 & 5.92 & 5.87 & 581 & 5.75 & 5.69 & 564 & 5.58 & 5.52 \\
\hline 26 & 5.94 & 5.89 & 582 & 5.77 & 5.71 & 5.66 & 5.60 & 5.55 & 5.49 & 5.43 \\
\hline 27 & 5.84 & 5.79 & $\tilde{5.73}$ & 5.67 & 5.62 & 5.57 & 5.51 & 5.46 & 5.40 & 5.34 \\
\hline 28 & 575 & 5.69 & 5.64 & 5.58 & 5.53 & 5.48 & 5.42 & 5.37 & 5.31 & 5.25 \\
\hline 29 & 5.66 & 5.60 & 5.55 & 5.49 & 544 & 5.39 & 5.33 & 528 & 5.22 & 5.16 \\
\hline 30 & 5.57 & 5.51 & 5.46 & 5.40 & 5.35 & 5.30 & 5.24 & 5.19 & 5.13 & 5.07 \\
\hline
\end{tabular}

well known WinkLeR's titration method, showed a constant Oxygen value. As a matter of fact there is a theoretical objection to the adoption of this method which must not be overlooked. If this method be employed at all, it is necessary to ensure very efficient circulation between the air in the bottle and the outside air, because 
11

from a free dry Atmosphere of $760 \mathrm{~mm}$. pressure

\begin{tabular}{|c|c|c|c|c|c|c|c|c|c|c|}
\hline $\mathrm{Cl}=10$ & $\mathrm{Cl}=11$ & $\mathrm{Cl}=12$ & $\mathrm{Cl}=13$ & $\mathrm{Cl}=14$ & $\mathrm{Cl}=15$ & $\mathrm{Cl}=16$ & $\mathrm{Cl}=17$ & $\mathrm{Cl}=18$ & $\mathrm{Cl}=19$ & $\mathrm{Cl}=20$ \\
\hline 9.63 & 9.51 & 9.39 & 9.26 & 9.14 & 9.01 & 8.89 & 8.76 & 8.64 & 8.52 & 8.39 \\
\hline 9.38 & 9.26 & 9.14 & 9.02 & 8.90 & 8.78 & 8.66 & 8.54 & 8.42 & 8.30 & 8.18 \\
\hline 9.13 & 9.01 & 8.90 & 8.78 & 8.66 & 8.55 & 8.43 & 8.32 & 8.20 & 8.08 & 7.97 \\
\hline 8.89 & $8.7 x$ & 8.67 & 856 & 8.44 & 8.33 & 8.22 & 8.11 & 8.00 & 7.88 & 7.77 \\
\hline 8.67 & 8.56 & 845 & 8.34 & 8.23 & 8.12 & 8.02 & 7.91 & 7.80 & 7.69 & 7.58 \\
\hline 8.45 & 8.35 & 8.24 & 8.14 & 8.03 & 7.93 & 7.82 & 7.72 & 7.61 & 7.51 & 7.40 \\
\hline 8.24 & 8.14 & 8.04 & 7.94 & 7.84 & 7.74 & 7.64 & 7.53 & 7.43 & 7.33 & 7.23 \\
\hline 8.05 & 7.95 & 7.85 & 7.75 & 7.65 & 7.56 & 746 & 7.36 & 7.26 & 7.16 & 7.07 \\
\hline 7.86 & 7.76 & 7.67 & 7.57 & $\pi .48$ & 7.39 & 7.29 & 7.20 & 7.10 & 7.01 & 6.91 \\
\hline 7.68 & 7.59 & 7.50 & 7.40 & 7.31 & 7.22 & 7.13 & 7.04 & 6.95 & 6.85 & 676 \\
\hline 7.51 & 7.42 & 7.33 & 7.24 & 7.15 & 7.06 & 6.97 & 6.89 & 6.80 & 6.71 & 6.62 \\
\hline 7.34 & 7.26 & 7.17 & 7.09 & 700 & 6.91 & 6.83 & 6.74 & 6.66 & 6.57 & 6.48 \\
\hline 7.19 & 7.10 & 7.02 & 6.94 & 6.85 & 6.77 & 669 & 6.60 & 6.52 & 6.44 & 635 \\
\hline 7.04 & 6.96 & 6.88 & 6.80 & 6.71 & 6.63 & 6.55 & 6.47 & 6.39 & 6.31 & 6.23 \\
\hline 6.89 & 6.82 & 6.74 & 6.66 & 6.58 & 6.50 & 6.43 & 6.35 & 6.27 & 6.19 & 6.11 \\
\hline 6.76 & 6.68 & 6.61 & 6.53 & 6.46 & 6.38 & 6.31 & 6.23 & 6.15 & 6.08 & 6.00 \\
\hline 6.63 & 6.55 & 6.48 & 6.41 & 6.34 & 626 & 6.19 & 6.11 & 6.04 & 5.97 & 5.89 \\
\hline 6.50 & 6.43 & 6.36 & 6.29 & 6.22 & 6.14 & 6.07 & 600 & 5.93 & 5.86 & 5.79 \\
\hline 6.38 & 6.31 & 6.24 & 6.17 & 6.10 & 6.03 & 5.96 & $\tilde{5} .89$ & 5.82 & 5.76 & 5.69 \\
\hline 6.26 & 6.20 & (j.13 & 6.06 & 5.99 & 5.93 & 5.86 & ร.79 & 5.72 & 5.66 & 5.59 \\
\hline 615 & 6.09 & 6.02 & 5.96 & 5.89 & 5.83 & 5.76 & 5.69 & 563 & 5.56 & 5.49 \\
\hline 6.05 & 5.98 & 5.92 & 5.86 & 5.79 & 5.73 & 5.66 & $\tilde{5} .60$ & 5.53 & 5.47 & 5.40 \\
\hline 5.95 & 5.88 & 5.82 & 5.76 & 5.69 & 5.63 & 5.56 & 5.50 & 5.44 & 5.38 & 531 \\
\hline $5.8 \tilde{5}$ & 5.78 & 5.72 & 5.66 & 5.59 & 5.53 & 547 & 5.41 & 5.35 & 5.29 & 5.22 \\
\hline 5.75 & 5.68 & 5.62 & 556 & 5.50 & 5.44 & 5.38 & 5.32 & 5.26 & 5.20 & 5.13 \\
\hline 5.65 & 5.59 & 553 & 5.47 & $\tilde{5} .41$ & 5.35 & 5.29 & 5.23 & 5.17 & 5.11 & 5.04 \\
\hline $5.5 \tilde{5}$ & 5.5() & 5.44 & 5.38 & 5.32 & 5.26 & 5.20 & 5.14 & 5.09 & 5.03 & 4.95 \\
\hline 5.46 & 5.41 & 535 & 5.29 & 5.23 & 5.17 & 5.12 & 5.06 & 5.00 & 4.95 & $4 . \times t i$ \\
\hline 5.37 & 5.32 & 5.26 & 5.20 & 5.14 & 5.09 & 5.03 & 4.97 & 4.92 & 4.80 & 4.78 \\
\hline 5.28 & 5.23 & 5.17 & 5.11 & 5.06 & 5.00 & 4.94 & 489 & 4.83 & 4.78 & 4.70 \\
\hline 5.19 & 5.14 & 5.08 & 5.02 & 497 & 4.91 & 486 & 4.80 & 4.75 & 4.69 & $4.6^{2}$ \\
\hline $5: 10$ & 5.05 & 4.99 & 4.93 & $4.8 x$ & 4.83 & 4.77 & 4.71 & 4.66 & 4.60 & 4.54 \\
\hline 5.01 & 4.96 & 4.90 & 4.85 & 4.79 & 4.74 & 4.68 & 4.63 & 4.58 & 4.52 & 4.46 \\
\hline
\end{tabular}

the partial pressures of the Oxygen and Nitrogen within the bottle will otherwise alter. Oxygen is in fact twice as soluble as Nitrogen; and the result is that its original proportion in the air inside the bottle will be diminished and that of the Nitrogen will be increased by shaking with water, unless the air be continually renewed all the 
CHAS. J. J. FOX

Table 12

\begin{tabular}{|c|c|c|c|c|c|c|c|}
\hline \multirow[b]{2}{*}{$t$} & \multicolumn{2}{|c|}{$\underset{\text { (Argon-free) }}{\text { Nitrogen }}$} & \multirow{2}{*}{ Fox } & \multirow[b]{2}{*}{$t$} & \multicolumn{2}{|c|}{$\begin{array}{c}\text { Nitrogen } \\
\text { (Argon-free) }\end{array}$} & \multirow{2}{*}{$\frac{\text { Oxygen }}{\text { fox }}$} \\
\hline & $\underset{\text { Bock }}{\text { Bohr \& }}$ & Fox & & & $\begin{array}{c}\text { Bohr \& } \\
\text { Bock } \\
\text { (corrected) }\end{array}$ & Fox & \\
\hline-2 & - & 0.02439 & 0.05206 & 25 & 0.01471 & 0.01463 & 0.02890 \\
\hline-1 & - & 0.02383 & 005062 & 26 & 0.01444 & 0.01443 & 0.02842 \\
\hline 0 & 0.02330 & 0.02328 & 0.04923 & 27 & 0.01420 & 0.01424 & 002794 \\
\hline 1 & 0.02281 & 0.02275 & 0.04794 & $\begin{array}{l}28 \\
29\end{array}$ & 0.01396 & 0.01407 & 0.02751 \\
\hline 2 & 0.02232 & 0.02224 & $0.0466 \tilde{5}$ & 29 & 0.01373 & 001389 & 0.02708 \\
\hline 3 & 0.02188 & 0.02175 & 0.04545 & 30 & 0.01348 & 0.01373 & 0.02665 \\
\hline 4 & 0.02144 & 0.02128 & 0.04431 & 31 & - & 0.01358 & 0.02627 \\
\hline 5 & 0.02103 & 0.02083 & 0.04321 & 32 & - & 0.01342 & 0.02590 \\
\hline 6 & 0.02062 & 0.02039 & 0.04215 & 33 & - & 0.01328 & 0.02554 \\
\hline 7 & 0.02023 & 0.01997 & 0.04115 & 34 & - & 0.01313 & 0.02519 \\
\hline 8 & 0.01985 & 0.01956 & 0.04019 & 35 & 0.01241 & 001300 & 0.02485 \\
\hline 9 & 0.01947 & 0.01916 & 0.03928 & 36 & - & 0.01286 & 0.02452 \\
\hline 10 & 0.01911 & 0.01878 & 0.03837 & 37 & - & 0.01273 & 0.02420 \\
\hline 11 & 0.01878 & 0.01842 & 0.03751 & 38 & - & 0.01261 & 0.02389 \\
\hline 12 & 0.01843 & 0.01808 & 0.03675 & 39 & - & 0.01248 & 0.02359 \\
\hline 13 & 0.01810 & 0.01774 & 0.03598 & 40 & 0.01154 & & \\
\hline 14 & 0.01777 & 0.01742 & 0.03526 & 41 & - & $\begin{array}{l}0.01236 \\
0.01224\end{array}$ & $\begin{array}{l}0.02530 \\
0.02302\end{array}$ \\
\hline 15 & 0.01746 & 0.01710 & 0.03455 & 42 & - & 0.01213 & 0.02275 \\
\hline 16 & 0.01716 & 0.01681 & 0.03388 & 43 & - & 0.01201 & 0.02249 . \\
\hline 17 & 0.01686 & 0.01653 & 0.03321 & 44 & - & 0.01189 & 0.02224 \\
\hline 18 & 0.01661 & 0.01625 & 0.03258 & & & & \\
\hline 19 & 001631 & 0.01599 & 0.03201 & $\begin{array}{l}45 \\
46\end{array}$ & $\begin{array}{c}0.01084 \\
-\end{array}$ & $\begin{array}{l}0.01178 \\
0.01166\end{array}$ & $\begin{array}{l}0.02100 \\
0.02177\end{array}$ \\
\hline 20 & 0.01602 & 0.01574 & 0.03144 & 47 & - & 0.01155 & 0.02155 \\
\hline 21 & 0.01575 & 0.01550 & 0.03091 & 48 & - & 0.01143 & 0.02134 \\
\hline 22 & 0.01549 & 0.01527 & 0.03038 & 49 & - & 0.01132 & 0.02114 \\
\hline 23 & 0.01522 & 0.01505 & $\begin{array}{l}0.02986 \\
0.02938\end{array}$ & 50 & 0.01035 & 0.01120 & 0.02095 \\
\hline 24 & 0.01495 & 0.01483 & 0.02938 & & & 0.01120 & 0.02995 \\
\hline
\end{tabular}

time. As pointed out above, the gas-phase as well as the liquidphase should always be analysed when employing these methods. It may be expected that this method would give too low values for Oxygen and too high values for Nitrogen. As a matter of fact this is just what the present writer found in using a method similar to that of JACOBSEN, in connection with some other work. If water be saturated with air in this way and then analysed, it is always found that the Nitrogen indicates a temperature lower than that of the saturation temperature and the Oxygen a higher temperature; but that if a current of air be drawn through the bottle (by means 
of a water-pump) while the bottle is rotating, that this apparent temperature-difference found, tends to disappear.

It appears that in JACOBSEN's determinations, there was no particular arrangement for the renewal of the air; to that extent the values may be expected to be low, and by a nearly constant percentage for different waters and temperatures, which might possibly be calculated, at all events approximately, from the dimensions of the bottle and the quantity of water taken.

The results of the observations here described, are collected in Tables 10 and 11 in the form in which they are perhaps most useful in Oceanography. Table 10 contains the number of cubjc centimeters of Nitrogen (together with Argon) absorbed by the open sea per litre from the free atmosphere, as a function of the temperature and Chlorine concentration. Table 11 gives the number of cubic centimeters of Oxygen absorbed under the same conditions. In both cases it is assumed that the atmosphere always at all temperatures, has a pressure of $760 \mathrm{~mm}$ when freed from water vapour (and $\mathrm{CO}_{2}$ ) and then always consists of $78.16 \%$ Nitrogen, $0.94 \%$ Argon and $20.90 \%$ Oxygen by volume.

The absorption coefficients, in per cc. of distilled water, of Nitrogen and Oxygen of $760 \mathrm{~mm}$. is of physical interest, in addition to the Oceanographical value of the Atmospheric partial pressures, which was the chief reason for the present investigation. They are therefore included here too, for the sake of completeness. As a matter of fact WINKLER's and BoHr and Bock's determinations were made before the discovery of Argon; and if the former's figures refer also to Nitrogen prepared from air, as appears to be probable from what has already been said above, there have hitherto never been published any figures relating to pure Nitrogen.

Table 12 contains the absorption coefficients, per cc., of pure Nitrogen of $760 \mathrm{~mm}$ partial pressure, calculated from the observations of BoHR and Bock and from those of the present writer; Estreicher's values for Argon have been adopted. In addition are included the values for Oxygen of $760 \mathrm{~mm}$. partial pressure from the writer's measurements.

In conclusion the writer desires here to record his great indeptedness to Mr. L. VeGard of the Physical Institute in the University of Christiania for invaluable help in the making of the measurements on which the present work is based. 

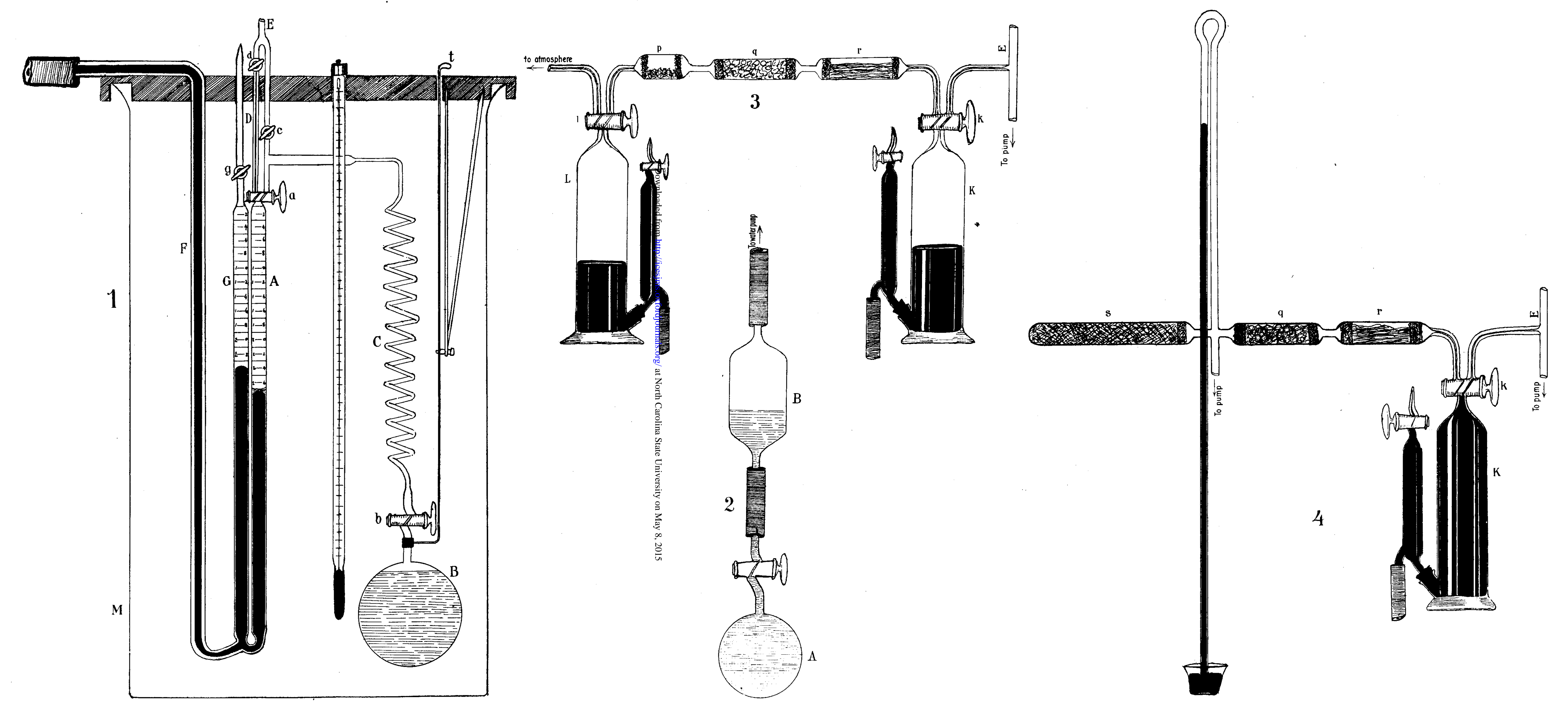